\title{
Technology impact on transformation of the labor markets and society sustainable development
}

\author{
Aleksandr Dzhioev* \\ Vladikavkaz Scientific Center of Russian Academy of Sciences, MarkusStr., 22, 362027 \\ Vladikavkaz, Russia
}

\begin{abstract}
New technologies have an ambiguous impact on the labor market, therefore, the possibility of sustainable development of modern society in the context of a radical transformation of the nature and content of labor is today the subject of controversy among world scientists and experts. Technological innovations of the last century reduced to a minimum jobs in labor-intensive sectors of the economy (for example, in agriculture), contributed to an increase in labor productivity, which allowed developed countries to invest in high technologies. The current stage of technological development is of a stochastic nature - new sectors of the economy appear unexpectedly, but grow very rapidly. Given the unpredictability of short-term and Long-team demand in the world's labor markets, social instability in the world is growing. The article substantiates the need to adapt society to new technologies that replace human labor by developing cognitive competencies, creative abilities, and strategic thinking.
\end{abstract}

\section{Introduction}

The knowledge economy is rapidly developing in the world, it is based on the complex automation of technologies for the production of goods and services and leads to a sharp increase in labor productivity and, as a result, to a massive release of those employed in traditional and economic sectors.

The world is on the verge of the beginning of the Fourth Industrial Revolution (Industry 4.0), which will be characterized by the virtuality of fully automated ultra-precise individual production, the complexity of the intelligent technologies used, the versatile range of applications of which will lead to fundamental changes not only in material goods. all spheres of society and human life, including his work, life and leisure.

In many works devoted to the study of the development of industrial revolutions to higher technological structures, most authors consider the main characteristics and essential aspects of the transformation of socio-economic systems under technological influence, identifying the features of the innovation cycle, and the structural dynamics of sectors of the economy. Certain aspects of the impact of technology on the transformation of the labor

\footnotetext{
*Corresponding author: dzhioevsasha@gmail.com
} 
market and the emergence of new areas of employment, especially in high-tech sectors of the economy, as well as other observed global changes in the world labor market, are considered in the works of B. Atrostic, D. Autor, E. Berman, A. Blinder, S. Broadberry, J. Bughin, D. Irwin, C. Frey, D. Dorn, K. Manuel, M. Osborne and others.

At the same time, insufficient attention has been paid to the problems of transforming labor markets as the most important institutions leading to the formation of technologies of the new industrial revolution, as well as to the problems of ensuring the sustainability of employment. Apparently, this is due to the fact that technological changes are taking place too quickly in the modern world. Thus, the most growing segment of the modern world economy is the virtual space, which is expanding every hour. The intensity of the spread of new technologies in the world is characterized by the data of the global report Digital 2020:

- the total number of Internet users at the beginning of 2020 amounted to 4.54 billion people, which is 298 million more than a year earlier;

- the audience of social networks in January 2020 reached more than 3.8 billion people, the annual growth of new users in social networks amounted to 321 million people;

- the number of Internet users at the beginning of 2020 was 4.5 billion people out of 7.7 billion people of the world's population, that is, $58.44 \%$ of the world's population regularly use the Internet;

- the number of mobile phone users on Earth at the beginning of the year was 5.19 billion people, which is 124 million more than a year earlier [1].

The topic of this study is relevant due to the importance of monitoring the impact of rapidly developing technologies on the transformation of the labor market conjuncture, as well as the need to identify factors to ensure sustainable development of society.

\section{Materials and Methods}

There is no consensus among analysts investigating the introduction of intelligent technologies in Industry4.0 about the possible consequences of mass layoffs of employed from traditional sectors of the economy. Some experts assess this influence as a positive phenomenon, predicting in the future an increase in labor productivity and wages, the maximum possible decrease in the share of unskilled and routine labor, the development of the creative content of labor in many professions, an increase in the quality of working life and a noticeable increase in the stability of society. Other experts, on the contrary, assess the introduction of intelligent technologies as a challenge to social and labor relations and sustainable development. They write that the main question generated by automation is whether robots will compete with or help workers. Considering different scenarios of interaction between robots and people, these researchers fear possible mass unemployment, predict a drop in income and a lack of employment prospects for people in entire sectors of the economy, write about the need to introduce an unconditional basic income in all countries that have introduced Industry4.0 technologies, in order to achieve social stability.

Due to the polarity of the opinions of scientists and experts, the theoretical basis of the study was the scientific work of various authors, in general, contradictory assessments of the impact of global technological trends on the formation of new trends in the labor market. The study also used analytical reports from expert groups of the Organization for Economic Cooperation and Development (OECD), the United Nations (UN), the United Nations Conference on Trade and Development (UNCAD), and the global institute of the consulting company McKinsey (Global Institute).

The methodological basis of the study was the evolutionary and systemic approaches, according to which the labor market is considered as a system that is being transformed under the influence of global factors of technology development and the introduction of innovations. 
The study used the following general scientific methods: analysis, synthesis, generalization, comparative analysis, methods of statistical data processing.

One way or another, all these materials show the undeniable impact of new technologies on the transformation of labor markets and the cognitive development of society.

\section{Results and Discussion}

According to St. N. Broadberry \& D.A. Irwin, scientific and technological changes lead to an increase in labor productivity, an increase in the innovative component of production and an increase in the standard of living [2]. They argue that the widespread use of information technology provides a competitive edge to multinationals through outsourcing, where a company employs highly skilled workers from developing countries and regions, managing business and operations from a central location. This conclusion is confirmed in the UNCTAD report "Digital Economy Report 2019", in which the authors write that a higher technological level of developed economies is associated with a lower unemployment rate [3].

A.Blinder agrees with these estimates, comparing the upcoming digital revolution with the third industrial revolution, which stimulated capital saving and created more favorable conditions for skilled labor than for unskilled labor. He notes that the new technologies of the industrial revolution had an extremely powerful impact on the primary sector of the economy, and at the beginning of the 20th century, in a short period of time, there was the largest release of employment in agriculture in the history of mankind. At the end of the 20th century, the final stage of industrialization began in developed countries, which had a noticeable impact on the structure of the labor market. Thus, in the penultimate decade of the 20th century, the number of agricultural workers in Japan and the United States, respectively, decreased by 2 and 3 times, while the number of jobs in technological sectors of the economy increased by 2-3 times. In the last decade of the 20th century, when most of Europe was struggling with unemployment, more than 8 million new jobs were created in the US in the service economy and high technology, attracting highly qualified personnel from European labor markets. However, A. Blinder concludes, according to these historical facts, it is impossible to assess the future changes in the structural transformation of labor markets either in the world or in individual developed countries, given that the scale of changes will be ten or one hundred times greater than the changes at the end of the century [4].

According to the McKinsey Institute, digital technologies will lead to the partial replacement of human labor by machines in the coming decades, and by 2036, up to $50 \%$ of work, expressed in working hours, can be automated, and by 2066 , automation may reach 46-99\%. The latest report from the McKinsey Institute says, that modern information technology since the beginning of the 21 st century has had an impressive impact on the structure of employment of people even in emerging markets, ensuring the flow of human resources from manufacturing to the service sector. Most modern business models are based on highly qualified skills such as research, development, design [5].

M. Mühleisen, Dan Andrews et al. in their study, they note that automation will be driven not only by routine physical, but also by intellectual processes. [6, 7]. The findings of these and other studies are based on the available evidence that both technology and trade increase inequality, and that in today's international competition, those with highly skilled workers win while maintaining the wage gap between skilled and unskilled workers $[8,9,10]$.

According to McKinsey experts, labor-saving innovations, in most cases, initially require additional training for employees, however, subsequently, when employees acquire the required skills, investments in training will increase productivity. As it follows from 
this, a more difficult situation can develop in countries where cheap labor has been and remains the main competitive advantage. Companies that disagree with the recognition that this methodology provides a competitive advantage will soon face bankruptcy [5].

However, there is also the opposite point of view. For example, the adherents of the Club of Rome believe that the service sector will not be able to provide jobs for all surplus labor, because it itself is subject to resource-saving changes, and unemployment will also grow here. Some economists believe that a possible decline in employment would be a consequence of the spread of new information technologies, if the expansion of demand does not compensate for the progress in labor productivity; and there is no institutional response to this mismatch by reducing the number of jobs other than the working period [11].

According to a number of scientists, there is a country-specific relationship between technological progress and employment. Assessing the impact of technological modernization on the transformation of the labor market and the structure of employment on the example of leading industrial countries in the past, J. Bughin notes that in the era of the industrial revolution, for example, in Japan, an effective model of technological modernization of production was built, which at the same time ensured the growth of labor productivity and employment population, contributing to a sharp rise in the competitiveness of the national economy.

In contrast, in Western European countries, according to a study by J. Bughin, most economies entered a vicious circle: to cope with growing international competition, national companies introduced labor-saving technologies, increasing production volumes, but freeing up jobs, especially in the manufacturing industry. The third industrial revolution, the author concludes, did not increase employment, so innovations are likely to lead to a reduction in employment in the European economy [12].

And in the United States, writes J. Bughin, although there were high rates of job creation, for the most part they were low-paid and low-productivity, especially in traditional services. Analyzing the development of the US service sector in our century, D. H. Autor \& D. Dorn show that, according to the laws of compensation theory, employment in the service Internet economy is growing at a rate no lower than employment in traditional labor-intensive sectors of the US economy is decreasing [13].

As the analysis of the scientific discussion has shown, the conclusions of the authors differ depending on the country as an object of research, industry affiliation and professional labor markets. Note that, in the opinion of most experts, the introduction of new technologies will not increase the unemployment rate, but the discrepancy in the level of wages, especially between export-oriented and developing countries. Hence the importance of macroeconomic policy, government support for exports, stimulating demand for high-tech products and other measures to increase competitiveness in developing countries through the introduction of new technologies. These conclusions are also important for Russia as a developing economy.

Consider the alternatives to digital development for Russia. Taking into account the place of Russia in the digital world, the community of Russian scientists was divided into two camps. From the point of view of the Russian Academy of Sciences (RAS), the main purpose of national economy digitalization is to achieve in Russia the same technology development level as in leading technological countries. To fulfill this goal, in 2015 a fiveyear medium-term import substitution program was introduced; in longer term it was proposed to transit national economy to a new technological structure and reindustrialization [14].

According to the second point of view of the Agency for Strategic Initiatives (ASI) and the Russian Venture Company (RVC), digital development of Russian economy should take direction towards creation of brand-new, non-existent markets [15]. They argue that 
Russian companies have a chance to dominate only in those markets that are not yet formed; imports substitution is less important than realizing exports potential since supporting and fostering domestic substitution industries with non-competitive products in terms of global markets only weakens national exports potential.

Now we can say that the second camp «won», and priority was given to promote promising technology markets that will be developed according to «road maps». However, we are supporters of the first camp and we believe that betting on exports promotion jeopardize national economic stability. Nowadays Russia has not economic, political and ecological problems, and we have to create comfortable conditions for science and technology development inside country. We believe that in near future the main instruments for development would become not the goods but technologies themselves. According to experts of the Russian Academy of Sciences, since 2014 the share of emigration of highly qualified specialists has doubled from 20 thousand peopleup to 44 thousand people by 2018. [16].

According to the statistical collection «Science Indicators: 2020» of the Higher School of Economics, total number of personnel engaged in research and development for the period from $2000-2018$ decreased from 887,729 people to 682,580 people(Table 1 ).

Table 1. Structure and dynamics of R\&D personnel in Russia, 2000-2018 [17, p.44].

\begin{tabular}{|l|c|c|c|c|c|c|c|}
\hline & $\mathbf{2 0 0 0}$ & $\mathbf{2 0 0 5}$ & $\mathbf{2 0 1 0}$ & $\mathbf{2 0 1 5}$ & $\mathbf{2 0 1 6}$ & $\mathbf{2 0 1 7}$ & $\mathbf{2 0 1 8}$ \\
\hline Total & 887729 & 813207 & 736540 & 738857 & 722291 & 707887 & 682580 \\
\hline Researchers & 425954 & 391121 & 368915 & 379411 & 370379 & 359793 & 347854 \\
\hline Engineers & 75184 & 65982 & 59276 & 62805 & 60441 & 59690 & 57722 \\
\hline Support staff & 240506 & 215555 & 183713 & 174056 & 171915 & 170347 & 160591 \\
\hline Others & 146085 & 140549 & 124636 & 122585 & 119556 & 118057 & 116413 \\
\hline
\end{tabular}

At the same time, the number of researchers with advanced degrees has also decreased from 105,911 people in 2000 to 100,330 people in 2018(Table 2).

Table 2. Researchers with advanced degrees in Russia, 2000-2018 [17, p.55].

\begin{tabular}{|l|c|c|c|c|c|c|c|}
\hline & $\mathbf{2 0 0 0}$ & $\mathbf{2 0 0 5}$ & $\mathbf{2 0 1 0}$ & $\mathbf{2 0 1 5}$ & $\mathbf{2 0 1 6}$ & $\mathbf{2 0 1 7}$ & $\mathbf{2 0 1 8}$ \\
\hline Researchers, total & 105911 & 99428 & 105114 & 111533 & 108388 & 103327 & 100330 \\
\hline $\begin{array}{l}\text { Doctor } \\
\text { sciences }\end{array}$ & 21949 & 23410 & 26789 & 28046 & 27430 & 26076 & 25288 \\
\hline $\begin{array}{l}\text { Candidate of } \\
\text { sciences }\end{array}$ & 83962 & 76018 & 78325 & 83487 & 80958 & 77251 & 75042 \\
\hline
\end{tabular}

The problem of scientists' aging remains for Russia. Although the share of $\mathrm{PhD}$ researchers under the age of 39 increased over the analyzed period from $19.4 \%$ to $27.3 \%$, the share of $\mathrm{PhD}$ researchers decreased from $2.4 \%$ to $2 \%$, while researchers over 60 years old were in $201935.4 \%$ among candidates of sciences and $69.7 \%$ among doctors of sciences. More than $51 \%$ of Russian researchers with an academic degree are over 70 years today (Table 3).

International comparisons of the number of personnel engaged in research and developmentaccording to 2018 data show that in Russia there are 106 researchers per 10,000 employed in the economy, in Thailand this figure is 229 people, in Denmark - 218 people, in Israel -212 people; 57 of them are researchers in Russia, 157 in Denmark, 153 in South Korea, and 148 in Sweden [17].

Together with those, Industry 4.0 is one of the most promising areas in Russia. It can give impetus to the innovative development of industry; more funds will appear for digitalization and development in general [18]. Manufacturing industries are among those potential beneficiaries of digitalization: it can decrease its labor intensity and minimize 
technological lag between Russia and developed countries. To date, experiments are already being carried out both in manufacturing and in other industries, where so-called "smart production" is not yet very active, but still being tested.

Table 3. Age structure of researchers in Russia, 2000-2018[17, p.51].

\begin{tabular}{|l|c|c|c|c|c|c|}
\hline & \multicolumn{3}{|c|}{$\mathbf{2 0 1 0}$} & \multicolumn{3}{|c|}{$\mathbf{2 0 1 8}$} \\
\cline { 2 - 7 } & $\begin{array}{c}\text { Researchers, } \\
\text { total }\end{array}$ & $\begin{array}{c}\text { Doctor } \\
\text { of } \\
\text { sciences }\end{array}$ & $\begin{array}{c}\text { Candidate } \\
\text { of sciences }\end{array}$ & $\begin{array}{c}\text { Researchers, } \\
\text { total }\end{array}$ & $\begin{array}{c}\text { Doctor } \\
\text { of } \\
\text { sciences }\end{array}$ & $\begin{array}{c}\text { Candidat } \\
\text { e of } \\
\text { sciences }\end{array}$ \\
\hline Total & 368915 & 26789 & 78325 & 347854 & 25288 & 75042 \\
\hline Under 29 & 71194 & 52 & 4354 & 60634 & 40 & 2507 \\
\hline $30-39$ & 59910 & 632 & 15229 & 92109 & 518 & 20459 \\
\hline $40-49$ & 54113 & 2394 & 12157 & 52801 & 2474 & 15466 \\
\hline $50-54$ & 42853 & 3086 & 8807 & 24159 & 1791 & 5538 \\
\hline $55-59$ & 45509 & 4125 & 9998 & 30673 & 2972 & 6772 \\
\hline $60-69$ & 60997 & 7743 & 16001 & 54077 & 8145 & 13693 \\
\hline $\begin{array}{l}70 \\
\text { andolder }\end{array}$ & 34339 & 8757 & 11779 & 33401 & 9348 & 10607 \\
\hline
\end{tabular}

In our opinion, the issue of structural unemployment, especially of people with special education, will not be so acute on the Russian labor market in the coming years, but the problem of a shortage of highly qualified personnel is obvious, as was shown above, even now. In the future, the shortage of highly qualified scientific and technological personnel in the Russian labor market will only grow. This circumstance will significantly limit the introduction of innovative technologies, because without the participation of specialists, paradoxically, the introduction of the digital economy and artificial intelligence is impossible. Therefore, in addition to the Strategy for Scientific and Technological Development of the Russian Federation and the State Program «Digital Economy of the Russian Federation», it is necessary to create a long-term program for the organization and implementation of new technologies in the training system.

Digital economy development in Russia can lead to a reduction in number of vacant jobs and liquidation of a certain number of professions, the emergence of a whole class of superfluous people, the destruction of the usual mechanisms of "guarantees of the future" (early recruitment or a decent pension), and the need for complete retraining of personnel to meet the requirements of the digital economy, said in an expert report prepared by the Young Professionals Union (WorldSkills Russia) «Skills of the future. What you need to know and be able to do in a new complex world». And here it is necessary to note the low level of use of digital technologies by business structures and the insufficient level of training of specialists for the digital economy. In 2016, the number of graduates of state educational institutions of higher education in the field of training "Informatics and Computer Engineering» was 7 people per 10,000 population, in 2017-2019 years -8 people per 10,000 population. For comparison with $2010-2013$ years the issue was only 2 people per 10,000 population. Training in the specialty "Robots and work-technical systems" in universities does not yet meet modern requirements. To ensure a technological breakthrough, Russia needs 1 million specialists employed in the ICT field, while today about 500 thousand programmers work in the country [19].

Based on the results of the study, several important conclusions can be drawn:

1. A review of the opinions of various expert communities shows that modern research does not yet give an unambiguous answer about the general impact of the technologies being introduced on the future conjuncture and the sustainability of the labor market development. 
2. The above generalizations of European, American and Japanese experience show that the introduction of new technologies leads not so much to a change in the number of jobs, but to their qualitative transformation and re-profiling, therefore, the employment of unskilled workers in developed markets has significantly decreased, while employment in high-tech industries has increased.

3. We can conclude that the development of Industry 4.0 is an objective and irreversible process, therefore, all countries and companies in order to achieve more competitive market positions will introduce modern intelligent technologies, constantly freeing people [13]. At the same time, developing countries, including Russia, are no exception.

4. Therefore, it can be assumed that with the digitalization of the Russian economy, the share of intellectual labor will increase, compared with traditional physical labor, which will allow in practice to use the so-called atypical types of employment on a large scale.

5. And it can also be predicted with a high probability that an increase in demand for the products of the new economy in conditions of growth in labor productivity should become a significant catalyst for the growth of employment in the service Internet economy of Russia.

\section{Conclusions}

New technologies in the coming decades will lead to the partial replacement of human labor by machine labor. Experts predict that both routine physical and intellectual processes will be automated, and the large-scale use of industrial robots and artificial intelligence will inevitably lead to the emergence of such new professions as a specialist in human interaction and artificial intelligence, which adapts human behavior in the human-machine system; information business analyst who provides database analysis and develops recommendations on this basis for optimizing business processes; a cyber city official who will ensure that the widely used digital processes of municipalities operate smoothly; specialist in genetic diversity; a conductor of a virtual store, a keeper of personal memories, etc. On the world labor market by 2030, it is predicted that about 50 million jobs of similar knowledge professions will appear, which will be available to any inhabitant of the planet.

Thus, the main role in government and corporate development strategies in the framework of the fourth industrial revolution will be played not by material factors, but by knowledge. Only a combination of the latest technologies and highly qualified specialists will ensure sustainable economic development in the foreseeable future and open up new opportunities for society: an increase in life expectancy, industrial and technological security, and the development of intellectual spheres of employment.

Industry 4.0 will inevitably lead to a qualitative transformation of the global labor market. In order to maintain social stability and ensure sustainable development of society, it is necessary to adapt society to technologies that replace human labor by developing strategic social competencies, creative thinking, and skills of conflict-free interaction in human-machine systems.

\section{References}

1. Digital 2020.WAS and Hootsuite (2020)

2. N.St. Broadberry, D.A. Irwin, Elsevier, 43(2), 257 (2006)

3. Digital Economy Report 2019. Value Creation and Capture: Implications for Developing Countries.United Nations Publications,UN Symbol: UNCTAD/DER/2019. Order from UN Publications (2019)

4. A. Blinder, Foreign Affaire, 85, 115 (2016) 
5. Twenty-five years of digitization: Ten insights into how to play it right. McKinsey Global Institute (2019)

6. M. Mühleisen, Finance \& Development, 55, 2, (2018)

7. D. Andrews et al., The 3rd annual conference of the Global Forum on Productivity (2018)

8. M. Cardone, T. Kretschmer, T. Strobel, Information Economics and Policy, 25 (2013)

9. R. Evangelista, P. Guerrieri, V. Meliciani, Economics of Innovation and New Technology, 23, 8, (2014)

10. Productivity Growth in the Digital Age, OECD (2019)

11. F. Postel-Vinay, International Economic Review, 3 (43), 737 (2002)

12. D.H. Autor, D. Dorn, American Economic Review, 5 (103), 1553 (2013)

13. J. Bughin, Chapter 3 in In Lee, ed, Encyclopedia of E-Business Development and Management in the Global Economy, Hershey (2010)

14. V.V. Ivanov, G.G. Malinetskiy, Innovations, 12 (230), 3 (2017)

15. NTI: opinions, estimates, forecasts.ASI (2017)

16. Russia was left without scientists and specialists, https: //lenta.ru/ (2018)

17. L.M. Gokhberg, K.A. Ditkovsky, E.I. Evnevich, Science indicators: 2020. Statistical collection (2020)

18. L.K. Gurieva, Mediterranean Journal of Social Sciences, 3 (2015)

19. R. Ryskal, Economy in figures, http://www.kommersant/ 